\title{
Women in Resistance: Reporting the impact of IEEE WiEUFRNexhibition at Science and Tech Week at UFRN
}

\author{
Monica Magalhães Pereira and Márjory Da Costa Abreu
}

${ }^{1}$ UFRN, \{monicapereira, marjory\}@ dimap.ufrn.br

\begin{abstract}
In celebration of the 60th anniversary of UFRN, we have proposed an initiative by IEEE WiEUFRNat CIENTEC aiming to highlight the female contribution to the STEM (Science, Technology, Engineering and Maths) degrees at UFRNover the last 60 years. The highlights were made through an exhibition, composed of four parts: I) description of renowned female icons and their contributions to the STEM areas. II) History of female participation in STEM courses at UFRN, through graphs showing the percentage of female students in the courses since its creation. III) \#euexisto campaign: display of testimonials videos from current students of STEM courses explaining why they chose the course. IV) Tribute to female Lecturers: display all female lecturers names that have taught in STEM courses at UFRN. As a result, the group paid a tribute to those brilliant women and highlighted their contribution to STEM; acknowledged the current students and teachers of the courses; and helped raising awareness about the need to encourage the participation of women in these courses and in order to build a more diverse environment. Our main goal was raise awareness that the degrees of STEM had consistently less women than man and thus, our feminist group had a very important role to play in increasing those numbers. From the informal feedback we received, we believe our goal was achieved.
\end{abstract}

\section{Introduction}

In 2018, the UFRNcelebrated its 60th anniversary [1]. One of the main events to celebrate this important milestone was the science, technology and culture week (from Portuguese - Semana de Ciência, Tecnologia e Cultura - CIENTEC), held in June, 2018 [2].

In order to contribute to this special edition and as a main goal of this paper, IEEE WiEUFRNgroup proposed an exhibition to discuss and raise awareness about the participation of women in STEM (Science, Technology, Engineering and Maths) at UFRN. The exhibition intended to instigate the public to question cultural practices in both academic and professional fields and reflect on the influence of male dominant culture on the choice and permanence of girls in the mentioned courses. In addition, the exhibition also sought to bring visibility to the current students and teachers of the courses, paying a tribute and appreciating their contribution.

During an entire day, IEEE WiEUFRNmembers presented each part of the exhibition, questioning the public what they think about female participation and how everyone can contribute to make his/hers study and work environment friendlier and free from harassment and sexual assault. The exhibition space featured an artistic design that highlighted the addressed topics. In addition, visitors were invited to leave their contribution on the subject in online social media by posting photos at our banner and leaving comments with the hashtag \#euexisto, carefully selected to this special occasion. 
The most relevant part of the exhibition was the displayed information regarding the female/male rate in STEM courses since the opening of the institution, showing the visitors how female participation has evolved throughout time. This study provoked an intense debate among the visitors on how slowly we have been seen the increase of female participation throughout the years, or even if we have seen it at all.

This paper is organised as follows. In Section 2 it will be presented the methodology adopted in order to plan and execute the IEEE WiEin CIENTEC. In Section 3, we detail how we executed our booth at CIENTEC with some pictures to illustrate. In Section 4, we present the numbers that were displayed during CIENTEC regarding the female lecturers and female students in STEM degrees at UFRN. And finally, in Section 5, we present our feedback of the impact we have made by just doing this booth at CIENTEC and our conclusions.

\section{Methodology}

The exhibition was design to be placed in a $3 \times 3 \mathrm{~m}$ booth. The booth's walls were used to display all the relevant information. The exhibition was divided in four parts:

I) Outstanding women and their contributions: description of female icons and their contributions to the STEM areas. The group selected ten outstanding women that have made remarkable contributions to STEM. The history and contribution of each woman were displayed in a card and suspended from the ceiling, so visitors could check front and verse.

II) History of the female participation in STEM courses at UFRN: wall chart, demonstrating the percentage of female students in STEM courses since their respective opening year at UFRN.

III) \#euexisto Movement: testimonials videos from current students of STEM courses explaining why they chose their course, which are the difficulties they face in an male dominated field and some advice to inspire young girls to pursue a STEM career.

IV) Tribute to female Lecturers: design of a mural listing the name of all female lecturers that have taught in one of UFRN's STEM courses.

In order to prepare each part, it was necessary to collaborate with many different departments and sectors, including the participation of other students from the Ramo IEEE UFRNbranch, lecturers and other departments that helped gather information about students and lecturers.

\section{Implementation}

In order to provide a detailed description on how the exhibition was implemented, next subsections will explain each part separately.

\subsection{Outstanding women and their contributions}

Since our first point was to celebrate important female icons for STEM, we have created a form and shared to students from STEM courses at UFRNrequesting the indication of one woman that has made a historical contribution to the field and a short description regarding her contribution. Despite the fact that we had a total of 17 names mentioned, there were many students who took part in this survey saying they did not know any woman with 
major contribution in STEM. This feedback was very important to the group because it demonstrated the urgent need to plan and execute other actions in order to disseminate the knowledge regarding STEM women and their contributions. From the 17 names, the 10 selected personalities were [3], [4], [5]: Ada Lovelace, Katherine Johnson, Edith Clarke, Margaret Hamilton, Enedina Marques, Marie Curie, Hedy Lamarr, Rosalind Franklin, Joana D'Arc de Souza, Valerie Thomas.

\subsection{History of the female participation in STEM courses at UFRN}

The IEEE WiEUFRNcounselor requested to Superintendência de Informática (SINFO) [6] the number of male/female students that entered each STEM course per year since the first year. A total of 33 courses among engineer, science and technology was analyzed. Some courses have almost 60 years, such as Chemical Enginnering and Electrical Enginnering and others have only 6 years, such as Bachelor in Information Technology.

SINFO provided a spreadsheet with all information and IEEE WiEUFRNmembers were responsible to analyze the information and plot charts showing the percentage of female versus male per year per course. This analysis is presented in Section 4.

\section{3. \#euexisto Movement}

The main goal of \#euexisto movement ("I exist" in a free translation) was to empower the current female students by showing they exist in many undergrad and graduation STEM courses and they resist in spite of all the challenges. As well as to inspire young girls who want to pursue a STEM career by seeing there are girls like them in those courses. Firstly, IEEE WiEUFRNmembers made a short movie to launch the movement in social media. The movie showed many IEEE WiEUFRNmembers saying one short sentence starting with "I exist in" and completing with the course or any other word that represents STEM. For instance: "I exist in Electrical Engineering". Then, the rest of the movie explains the movement and invites female students from all STEM courses to collaborate and send their own video explaining why they chose the course, the challenges they face and leaving an advice to inspire other girls [7]. To promote the movement we have organized a meeting called "IEEE WiELove Coffee," and invited many female students to have some coffee with the group and record their video.

After the movement launch on social media and the meeting, we have received 26 videos from female students from various STEM courses, which produced a single video with around $\mathbf{2 6}$ minutes. The videos were compiled, received subtitle and played during the exhibition.

\subsection{Lecturer names}

The IEEE WiEUFRNcounselor requested to Superintendência de Informática (SINFO) the names of all female lecturers that have worked in STEM courses, including current and retired lecturers, temporary lecturers, as well as the ones that are currently working in another institution or department not related to STEM courses. The main goal was to pay a tribute to all the women who made the history of the university and, in many cases, who paved the way for all current students and lecturers. The names were displayed by course in a mural. Many students, alumnus, lecturers and former lecturers visited the booth and could see their own names or the names of their former teachers on the mural. 


\section{Results}

This section discusses the overall results and focus mainly on the analysis of the data presented on the topic History of the female participation in STEM courses at UFRN.

During the 13 hours of exhibition, from 8 a.m to 9 p.m, around 120 people have visited the booth, from different ages and gender. Most of them had no knowledge about IEEE WiE. The immediate result was the increase in the number of followers in IEEE WiEUFRNprofile on social media, Instagram and Facebook. The visitors also posted many photos and comments tagging the group, which helped to increase group's popularity. Moreover, many female students from STEM courses in UFRNbecame interested in joining the group after visiting the exhibition. Some of them have applied to the selection process started on August 2018. Due to the exhibition, the group also received invitations to collaborate with others social projects with other groups and female Researchers and Lecturers.

The most relevant result from this exhibition was the discussion about female/male entrance rate. This topic raised a debate among the visitors regarding the low participation of young women in STEM courses. Many of them were impressed by the numbers and questioned why such low participation and what can be done to reverse the numbers. Since there are 32 STEM courses in the university, for sake of clarity, the courses were split in different charts. Figures 1,2, 3, and 4 show the female entrance rate per year in last five years up to 2017. It is important to observe $\mathrm{Y}$ axis intervals are different among charts, from 0 to $50 \%$ in figures 1 and 2, from 0 to $80 \%$ in 3 and from 0 to $100 \%$ in 4 . This choice was made in order to provide a better reading among different courses.

It is possible to observe that courses that are considered "male" courses by the general population have very low female entrance rate. Even the ones with more than 40 years, such as Electrical Engineering, shown in Figure 1, with around 20\% rate and 47 years. As well as Computer Engineering with less than 7\% rate in 2017 and 21 years old. For younger courses, the result is the same. Information Technology, in Figure 1 has only 6 years and female student entrance rate about $8.5 \%$ in 2017 . On the other hand, courses considered more "female" to general population have higher female entrance. In 6 years of existence, Environmental Engineering, shown in Figure 3, presents $42 \%$ of female entrance rate in 2017 and Architecture, 50\% in 2017, achieving 81\% in 2016, with 43 years. In order to base "male" and "female" courses, the authors considered the impressions collected from visitors during the exhibition.

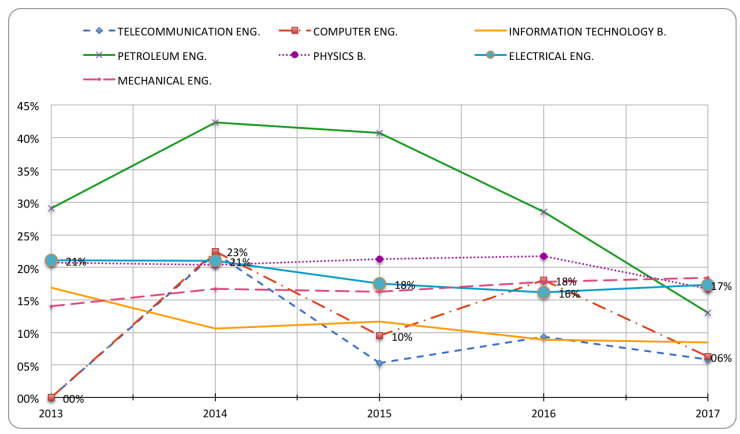

Figure 1. Average female student entrance rate per course I

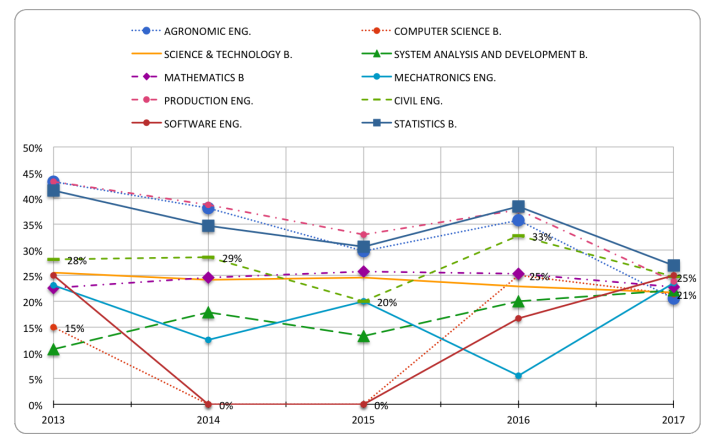

Figure 2. Average female student entrance rate per course II 


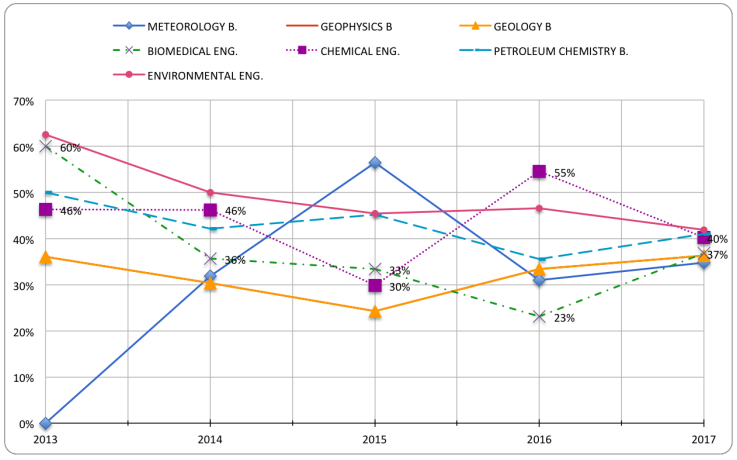

Figure 3. Average female student entrance rate per course III

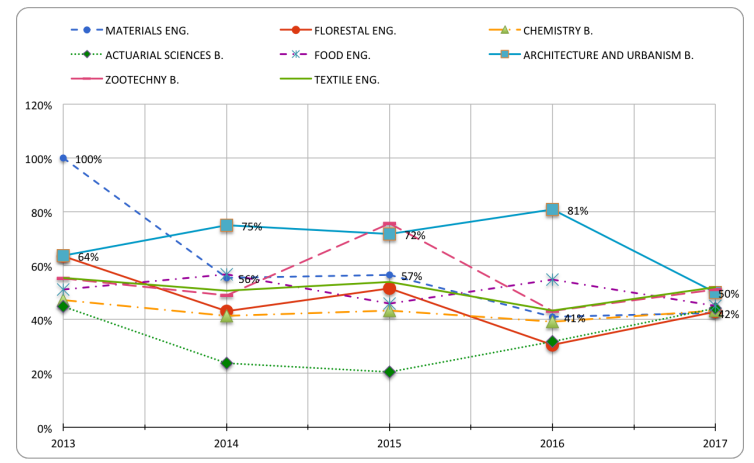

Figure 4. Average female student entrance rate per course IV

At a first analysis, three key observations can be made: 1. "Male" courses still presents a low female entrance; 2 . For most courses, it was observed a slightly change or no change at all in the past five years; 3 . The major changes are not that representative and, considering the numbers represent the past 50 years, the change is very slow.

In spite of that, this study requires further analysis. There are some particularities regarding some of the courses. For instance, many courses became a two-cycle course in the past years. Which means that the student starts in a more general course (Science and Technology or Information Technology), and after a few years, they are allowed to switch to their major course, such as Computer Engineering and Computer Science. This is the reason Computer Science presents 0\% entrance rate in 2014 and 2015, in Figure 2.

\section{Conclusions}

A general analysis of the project outcome shows that we have achieved all the planned objectives which were: raise awareness to the fact STEM degrees are attended mostly by male students as well to pay tribute to the women who have work in such hostile environments. We have managed to address a very relevant topic that is the participation of women in STEM courses for a significant audience. We presented several women who had made important contributions to technology, engineering and science. We started a debate on the lack of women in STEM courses. And finally, we have started a movement to give visibility to female students, in which they were the protagonists and inspiration to other girls.

\section{References}

\footnotetext{
[1] Portal da UFRN. "Assembléia Universitária Celebra 60 anos da UFRN", 2018. Available: http://www.UFRN.br/imprensa/noticias/17514/assembleia-universitaria-celebra-60anos-da-UFRN. [Accessed: September 05, 2018].

[2] CIENTEC UFRN. "Mostra de Ciência, Tecnologia e Cultura", 2018. Available: https://sigeventos.UFRN.br/evento/CIENTEC2018. [Accessed: September 05, 2018].

[3] Ignotofsky, Rachel, Women in science: 50 fearless pioneers who changed the world, Ten Speed Press, 2016.

[4] Federaćão Nacional de Engenheiros. "Mulher e engenharia no Brasil: história de desbravadoras", 2018. Available: https://www.fne.org.br/index.php/todas-as-noticias/4060mulher-e-engenharia-no-brasil-historia-de-desbravadoras/ [Accessed: September 05, 2018].

[5] EDUCAFRO. "Personalidades 2017: Joana D'Arc Felix", 2018. Available: https://www.educafro.org.br/site/personalidades-2017-joana-darc-felix/ [Accessed: September 05, 2018].

[6] Superintendência de Informática - UFRN, 2018. Available: https://info.UFRN.br/. [Accessed: September 05, 2018].

[7] IEEE WiEUFRN- Women in Engineering, 2018. Available: https://www.facebook.com/IEEE WiE.UFRN/videos/1727621653943613/. [Accessed: September 05, 2018]
} 